\title{
Immunostimulatory monoclonal antibodies for cancer therapy
}

\author{
Ignacio Melero*, Sandra Hervas-Stubbs*, Martin Glennie ${ }^{\ddagger}$, Drew M. Pardolls \\ and Lieping Chen $\$$
}

Abstract | Increasing immune responses with immunostimulatory monoclonal antibodies (mAbs) directed to immune-receptor molecules is a new and exciting strategy in cancer therapy. This expanding class of agents functions on crucial receptors, either antagonizing those that suppress immune responses or activating others that amplify immune responses. Complications such as autoimmunity and systemic inflammation are problematic side effects associated with these agents. However, promising synergy has been observed in preclinical models using combinations of immunostimulatory antibodies and other immunotherapy strategies or conventional cancer therapies. Importantly, mAbs of this type have now entered clinical trials with encouraging initial results.

Monoclonal antibody A unique immunoglobulin of known specificity that is produced by a B-lymphocyte clone usually immortalized by cell fusion with a non-secreting myeloma cell line.

* Centro de Investigación Médica Aplicada (CIMA) and Clínica Universitaria, Universidad de Navarra, Pamplona, Spain. ¥Tenovus Research Laboratories, Cancer Sciences Division, Southampton University School of Medicine, General Hospital, Southampton, UK. $\S$ Department of Oncology, Johns Hopkins University School of Medicine, Baltimore, Maryland USA. 'Department of Dermatology, Johns Hopkins University School of Medicine, Baltimore, Maryland, USA. Correspondence to I.M. and L.C.

e-mails: imelero@unav.es; Ichen42@jhmi.edu doi:10.1038/nrc2051
The immune system is regulated by a highly complex balance of signals transmitted by stimulatory and inhibitory receptors. More than any other discovery, monoclonal antibodies (mAbs) ${ }^{1}$ have enabled us to both identify and manipulate these molecules, providing an important new class of immunostimulatory therapeutics that can complement small-molecule therapeutics under active development ${ }^{2}$. Specific recognition by $\mathrm{mAbs}$ has permitted the identification of cytokines and cell-surface molecules involved in humoral (antibodymediated) and cellular immune responses. Moreover, $\mathrm{mAbs}$ have specificity for their target molecules and the ability to either activate (agonistic mAbs) or suppress (antagonistic mAbs) the molecular function of the target. Immunostimulatory $\mathrm{mAbs}$ can be defined as agents that enhance ongoing immune responses. As such they have the potential to increase the immune response to tumours, which is suppressed in many cancer patients through various mechanisms $\mathrm{s}^{3,4}$.

\section{Stimulating immunity in cancer patients}

The rejection of tumour cells requires an orchestrated set of events mediated by several types of leukocytes including $\mathrm{CD}^{+}$and $\mathrm{CD}^{+} \mathrm{T}$ lymphocytes, dendritic cells (DCs) and natural killer (NK) cells (FIG. 1). At tumourdraining lymph nodes, each $\mathrm{T}$ lymphocyte with its exclusive T-cell receptor (TCR) has the opportunity to scan DC surfaces for a specific antigenic peptide complexed with either major histocompatibility complex (MHC) class I or class II molecules. Signalling from the TCR is the primary trigger of antigen-driven lymphocyte division, survival and differentiation into effector or memory T lymphocytes (FIG. 2), but paradoxically it can also lead to tolerance. Tolerance is mediated by either the elimination of the antigen-specific T cells through the induction of apoptosis (clonal deletion) or by functional paralysis of the antigen-specific $\mathrm{T}$ cells (anergy) $)^{5}$. The hazardous decision to initiate or abort a cellular immune response mainly relies on the innate detection by antigen-presenting DCs of biomolecules that signify danger ${ }^{6}$ in the form of the presence of microbes, stressful cell death or inflammation ${ }^{7}$. Intercellular communication to initiate, repress or fine tune the cellular immune response is mediated by soluble cytokines and many receptor-ligand pairs on the surface of juxtaposed leukocytes (FIG. 2).

Once fully activated, T lymphocytes reach peripheral tissues with a preference for regions with inflammatory vascular endothelium. Activated $\mathrm{CD}^{+} \mathrm{T}$ cells, once loaded with cytolytic machinery, kill target cells that express the target antigen complexed with a small number of MHC class I molecules. Activated CD4 ${ }^{+}$ $\mathrm{T}$ cells can also mediate tumour cell destruction, promote inflammation, cooperate in the induction of CD8 ${ }^{+}$cytotoxic T lymphocytes (CTLs) and help B cells to produce cell-destructive anti-tumour antibodies.

A wide array of regulatory mechanisms of the immune system are exploited by tumours to avoid or suppress the immune response $e^{3,4}$. These include specialized T-cell subsets that repress cellular immunity 


At a glance
- Monoclonal antibodies (mAbs) have had a significant effect on current practice in
oncology. Mechanisms of action include direct tumour cell destruction and indirect
targeting of growth and pro-angiogenic mediators.
- Using mAbs to stimulate the immune response against cancer cells is a new indirect
mode of action, achieved by either blocking inhibitory 'immune checkpoint'
receptors such as cytotoxic T-lymphocyte-associated protein 4 (CTLA-4, also known
as CD152) or triggering activating receptors such as 4-1BB or CD40.
- The list of mAbs that have clearly shown these kinds of effects in mouse tumour
models is expanding, and can be grouped as mAbs that interfere with lymphocyte
inhibitory receptors; mAbs that function as agonist or super-agonist ligands for co-
stimulatory receptors; mAbs that enhance the activation and/or maturation of
antigen-presenting cells (APCs); and mAbs that delete or inhibit immunosuppressive
mechanisms such as regulatory T cells.
- An obstacle to the application of immunostimulatory mAbs is their associated
adverse toxicity, most commonly reversible autoimmunity and/or systemic
inflammatory reactions.
- Anti-CTLA-4, anti-4-1BB and anti-CD40 are the first immunostimulatory mAbs to
reach the clinic. Anti-CTLA-4 is in phase III clinical trials for patients with malignant
melanoma following successful phase II testing. Importantly, organ-specific
autoimmunity was reported in about one third of patients and correlated with
clinical response.
- Synergistic combinations of immunostimulatory mAbs have been identified at the
preclinical level, and combinatorial strategies with cancer vaccines, adoptive T-cell
therapy, radiotherapy and chemotherapy will probably have important roles in
future clinical development.

Cellular immune response An immune response that is predominantly mediated by activated lymphocytes and macrophages, resulting in inflammatory infiltrates such as those seen in granulomas.

\section{Dendritic cells}

A network of leukocyte populations that present antigen captured at peripheral tissues to T cells in lymphoid organs through both MHC class II and I antigen-presentation pathways. The MHC class II presentation pathway mainly presents endocytosed antigens to $\mathrm{CD} 4{ }^{+} \mathrm{T}$ cells, whereas $\mathrm{MHC}$ class I molecules generally present peptides from the endogenously synthesized proteome to $\mathrm{CD}^{+}{ }^{+} \mathrm{T}$ cells

\section{Natural killer cells}

A lymphocyte type involved in cytolytic functions that is also exploitable in immunotherapy. These cells share many features with CTLs, but lack a TCR. NK cells are also

decorated with receptors that activate cytotoxicity on contact with stressed, virally infected, transformed or antibodycoated cells. In addition, they are equipped with receptors that inhibit cytotoxicity if detecting normal MHC class I molecules on the target cell. (regulatory T cells; $\mathrm{T}_{\mathrm{Reg}}$ cells) and a plethora of soluble factors such as interleukin 10 (IL10), vascular endothelial growth factor (VEGF) and transforming growth factor- $\alpha$ (TGF $\alpha)$ (FIG. 1). In fact, successful escape from immune surveillance is considered one of the necessary hallmarks of cancer ${ }^{8}$.

A range of strategies are being considered to use the immune system in the fight against cancer (cancer immunotherapy), including immunostimulatory and inhibitory mAbs, cancer vaccines ${ }^{9}$, immunostimulants to increase the immunogenicity of tumour cells and adoptive transfer of cultured activated $\mathrm{T}$ lymphocytes (adoptive T-cell therapy) ${ }^{10}$.

\section{Advantages of immunostimulatory mAbs}

IgG $\mathrm{mAbs}$ are large, complex proteins that are resistant to degradation in serum and have molecular features that ensure they remain in the circulation for an extended period $^{11}$. However, the advantage of a long half-life is accompanied by the problem of slow reversal of toxicity following treatment; removing $\mathrm{mAbs}$ from the circulation is difficult and requires complicated procedures such as repeated plasmapheresis.

To avoid the intrinsic immunogenicity of rodent mAbs, these biomolecules are currently genetically engineered to replace immunogenic mouse sequences with human ones (leading to an antibody that is 95\% human $)^{11,12}$, made from human $\mathrm{mAb}$ phage libraries or produced in mice that are transgenic for the human immunoglobulin loci ${ }^{13,14}$. Such therapeutic antibodies are distinguishable from endogenous immunoglobulin only in their antigen-binding site (idiotope) so quantitative assays to assess their pharmacokinetics must rely on immunoassays using recombinant antigen adsorbed to plastic dishes or specific anti-idiotype monoclonal antibodies when available. The advent of technology for humanizing or producing fully human antibodies has revolutionized $\mathrm{mAb}$ therapeutics, enabling repeat dosing without inducing anti-antibody immune responses in the patient in a way that was not possible with the original rodent antibodies.

Doses in humans are typically about 2-20 mg per kg (body weight), and most regimens involve repetitions at 2-8 week intervals. Therefore, expensive 100-200 g Good Manufacturing Practice (GMP) compliant batches are required for quality control, toxicology and clinical trials.

The bivalency of the antigen-binding sites of mAbs, together with the potential for hypercrosslinking by Fc receptors on neighbouring leukocytes, provides the capacity to crosslink proteins such as cell-surface receptors (frequently associated with agonist antibodies), obstruct protein-protein recognition or induce conformational changes in the bound target protein. MAbs frequently bind to their antigens with several-fold higher affinity than the natural ligands. These molecular mechanisms bestow $\mathrm{mAbs}$ with diverse functional capacities as agonists or antagonists of immune system signalling mediated by their target proteins ${ }^{15}$.

Although new mAbs can sometimes have dramatic immunostimulatory activity, and have produced potent anti-tumour responses, such potency can come at a cost: toxicity. Two types of target-related toxicity have been described; the generalized systemic induction of pro-inflammatory mediators (induction of a cytokine storm) that can cause life-threatening systemic inflammatory syndrome or cytokine release syndrome (BOX 1), and organ-specific autoimmunity that has so far been transient and reversible on antibody clearance.

\section{MAbs that increase co-stimulation}

$\mathrm{T}$ cells are activated when they bind antigen presented by antigen-presenting cells (APCs) through their TCRCD3 complex. T cells also express several co-signalling molecules, typically cell-surface glycoproteins, that direct, modulate and fine tune TCR signals ${ }^{16}$ (FICS 1, 2). As a consequence, these membrane molecules positively and negatively control the priming, growth, differentiation and functional maturation of a T-cell response. The functional effects on T-cell activation classify co-signalling molecules as co-stimulators or coinhibitors. Co-signalling molecules engage their ligands in organized patches of cell-cell interaction between $\mathrm{T}$ cells and APCs, termed immunological synapses ${ }^{17}$. Most of the defined co-signalling molecules belong to either the immunoglobulin ${ }^{16,18}$ or the tumour-necrosis factor receptor (TNFR) superfamilies ${ }^{19,20}$ (FIG. 2).

CD28. The two-signal model of T-cell activation postulates the existence of two types of signals: antigendependent TCR-mediated signals are termed signal 1 and antigen-independent co-stimulatory signals are termed signal 2 . The classic signal 2 is delivered by the CD28 molecule (expressed by the T cell) on 


\section{T-cell receptor}

Surface receptors expressed on $T$ cells that recognize specific peptides complexed with $\mathrm{MHC}$ molecules that convey intracellular signals through associated CD3 molecules. As a result of rearrangement of its genes during T-cell ontogeny, a clonally distributed array (repertoire) of receptors is generated.

Memory T lymphocytes Some of the activated $T$ cells in the $\mathrm{CD} 4^{+}$and $\mathrm{CD} 8+$

compartments become long lived, whereas most effector T lymphocytes die off. Surviving cells are termed memory $T$ lymphocytes. Lower stimulation thresholds help to re-activate these cells after antigen re-exposure.

Regulatory T cells $\mathrm{T}_{\mathrm{Beg}}$ cells are defined by their expression of the FOXP-3 transcription factor, and are important inhibitors of immunity. $T_{\text {oeg }}$ cells express CD25, CTLA-4, GITR and LAG3 in a constitutive fashion.

Contact with $\mathrm{T}_{\text {Reg }}$ lymphocytes can directly inhibit $\mathrm{T}$ and $\mathrm{NK}$ cell activation, or indirect inhibition can take place through APCs.

\section{Plasmapheresis}

The procedure of circulating the blood of a patient in an extracorporeal closed system that eliminates autologous plasma at the same time as returning the cellular components and transfusing donated plasma.

Fully human mAbs Antibodies rearranged in immunized mice that are transgenic for the human heavy and light immunoglobulin regions and therefore produce human immunoglobulins.

\section{Good manufacturing} practice

A set of regulations, codes and guidelines for the fabrication of drugs. GMP involves normalized production in a contaminant-free ambient environment, quality contro and labelling and toxicology studies to ensure the purity, identity, traceability, stability and activity of the

administered drug formulation The philosophy is to avoid contaminations, mistakes or variations, thereby achieving more safety for patients.

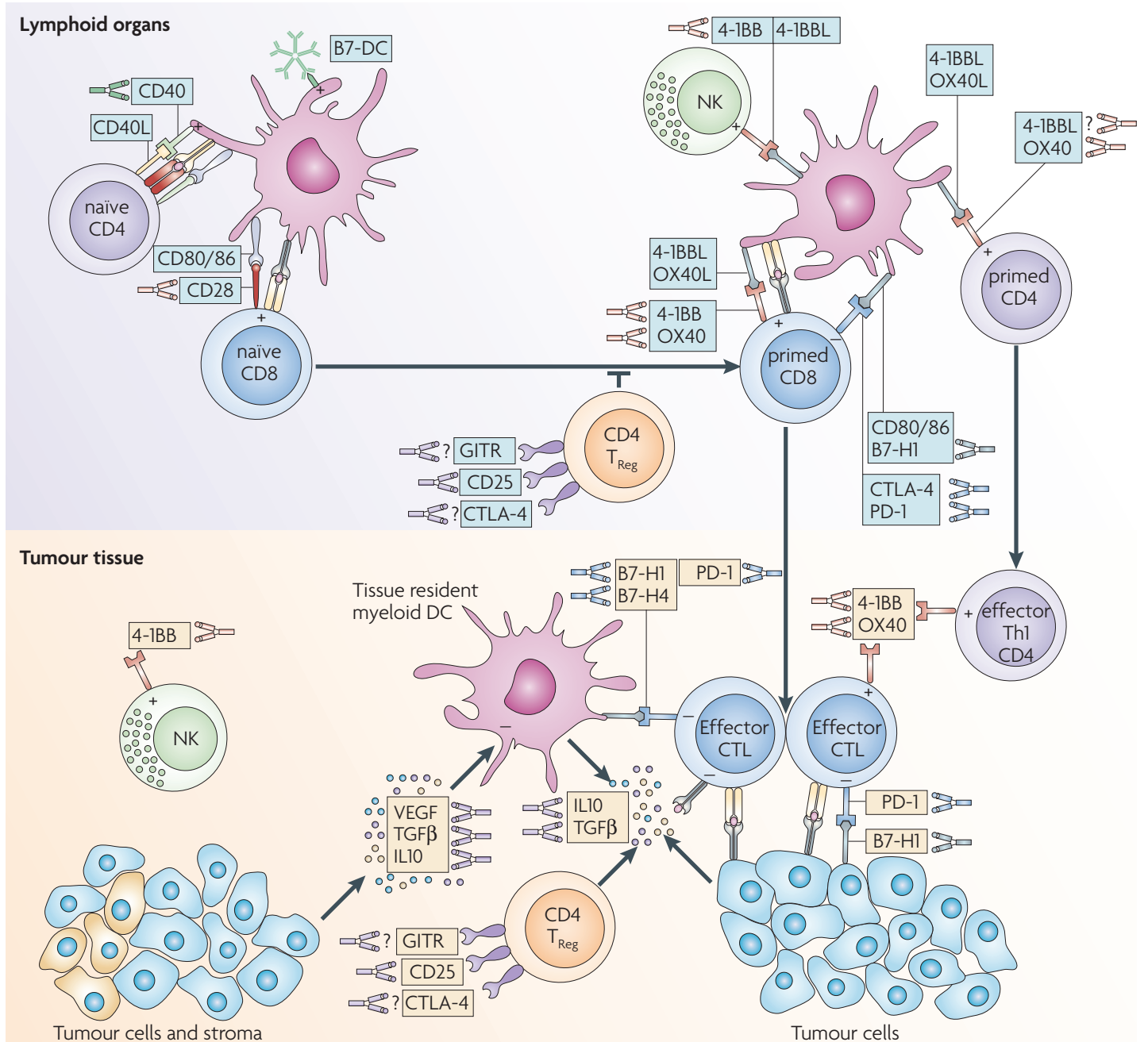

Figure 1 | Schematic representation of points of intervention with immunostimulatory mAbs. The rejection of tumour cells is an orchestrated set of events mediated by several types of leukocytes. The molecular and cellular networks that define the intensity of the response can be artificially altered with mAbs that act on the indicated surface glycoproteins. An optimal immune response is thought to be initiated by an activated and/or mature dendritic cell (DC) presenting optimal levels of antigen in lymphoid tissue. Anti-tumour effector CD4 ${ }^{+}$and $C D 8^{+}$lymphoblasts are generated in a highly regulated fashion that sets the threshold of activation, prevents overactivation of the system and limits the size of clonal expansion. Natural killer (NK) cells can contribute to the anti-tumour response by promoting inflammation, activating DCs and tumour lysis that can provide malignant cell debris for cross-presentation by DCs. The immune response towards tumour antigens is orchestrated in lymphoid tissue (typically lymph nodes) that drain the tissue in which the tumour is situated and then activated lymphocytes can potentially infiltrate tumour tissue to mediate tumour cell destruction. This is limited by several suppressive mechanisms that are mediated by regulatory $T$ cells $\left(T_{\text {Reg }}\right.$ cells), myeloid cells present at the tumour site and soluble factors such as transforming growth factor- $\beta$ (TGF $\beta$ ), interleukin 10 (IL10) and vascular endothelial growth factor (VEGF). Molecular targets for immunostimulatory $\mathrm{mAbs}$ are indicated by an antibody pointing to the name of each molecule. From a pharmacodynamic point of view, immunostimulating mAbs can be classified in the following categories indicated by colours: (red) mAbs that promote the function of a lymphocyte receptor (agonists) involved in immune activation; (blue) mAbs that interfere with the function of a lymphocyte receptor involved in inhibiting or regulating the immune response; (green) mAbs that promote the function of the professional antigen-presenting cells (APCs) such as DCs that present antigen to T-lymphocytes; (purple) mAbs that interfere with inhibitory molecules expressed by the tumour or cells in the tumour microenvironment that contribute to immune evasion.

binding to the ligands CD80 (also known as B7-1) or CD86 (also known as B7-2) on the APC. The combination of signal 1 and 2 is thought to be crucial for effective T-cell activation ${ }^{21,22}$. CD28 is an immunoglobulin superfamily member constitutively expressed on the membrane of most resting $\mathrm{CD} 4^{+} \mathrm{T}$ lymphocytes and on about half of the CD8 ${ }^{+} \mathrm{T}$ cells ${ }^{21}$. After engaging with its ligand, CD28 induces signalling cascades that increase proliferation, intensify cytokine secretion, upregulate the expression of anti-apoptotic genes and increase energy metabolism to support lymphoblast activation $^{21,22}$. 

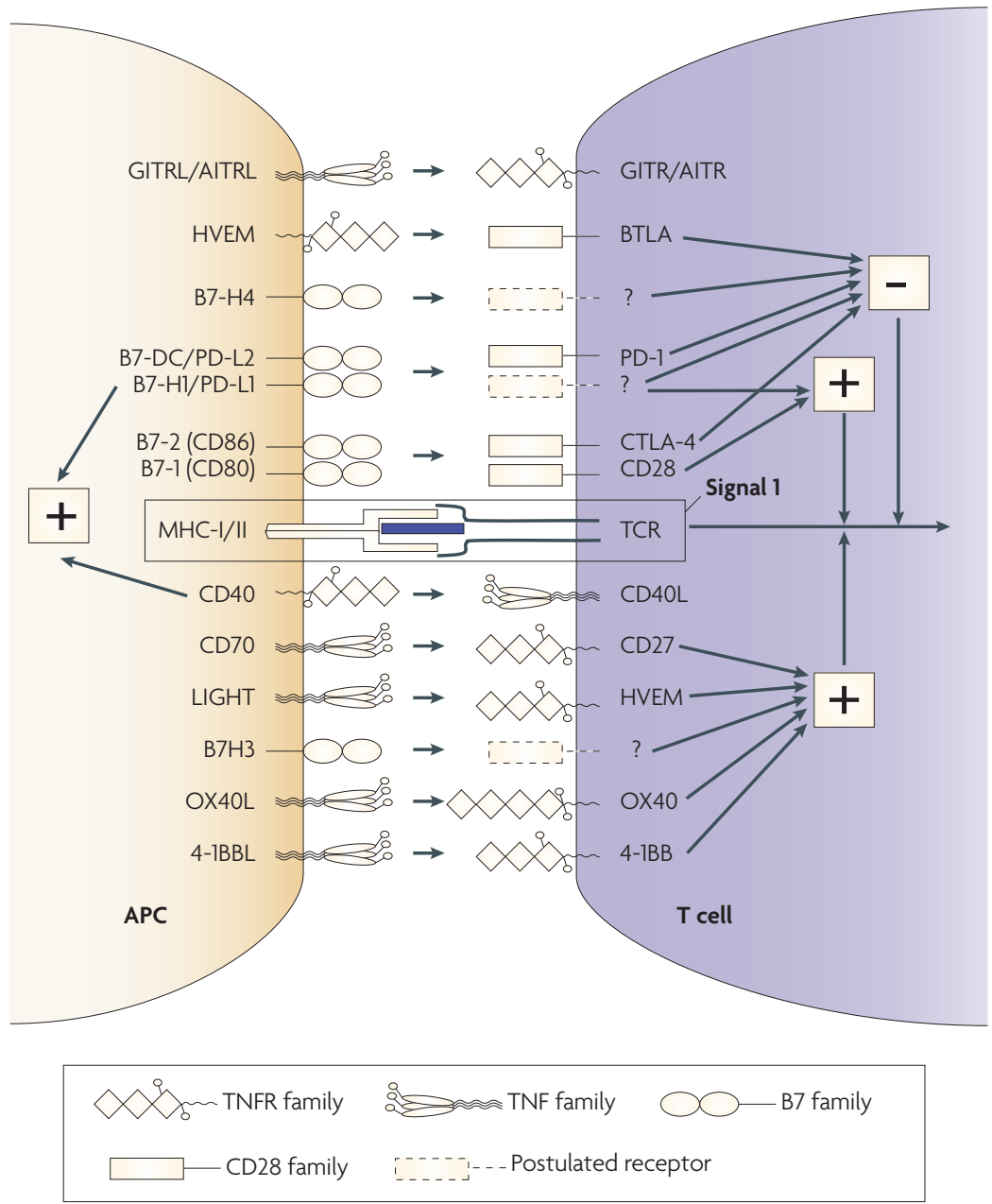

Figure 2 |Co-stimulatory and co-inhibitory molecules targeted by

immunostimulatory mAbs. A schematic representation of surface co-signalling molecules on T cells relevant in cancer immunotherapy interacting with their ligands on an antigen-presenting cell (APC). These surface molecules belong to the tumour necrosis factor (TNF) receptor and immunoglobulin families, and their stimulation or inhibition can be exploited to increase the cellular immune response against cancer. The overactivation of co-stimulatory signals and inactivation of co-inhibitory functions can be artificially achieved by agonist and antagonist monoclonal antibodies (mAbs).

Some of these lymphocyte surface molecules are constitutive (such as CD28), some are constitutively expressed on some cells and are inducible on others (such as CD27 and CD40), whereas others are induced only after antigen priming (such as cytotoxic Tlymphocyte-associated protein 4 (CTLA-4), 4-1BB, OX40, CD40L, BTLA and GITR), and are therefore selectively expressed on responding lymphocytes. Inducible expression targets are conceivably more selective and less likely to cause systemic inflammatory syndromes.

Bivalency

As a result of having two antigen-binding sites in each immunoglobulin molecule, antibodies can engage two antigens simultaneously.

Tumour antigens

Mutated, altered, viral or hyperexpressed protein

sequences in cancer cells that can be recognized by

T lymphocytes.
Tumour cells that have been transfected with either CD80 or CD86 expression cassettes show increased immunogenicity, leading to regression and vaccination against the original tumour cells that are not transfected with either ligand ${ }^{23,24}$. Antibodies against CD28 are known to potentiate anti-tumour immunity in combination with bi-specific antibodies that bind both a surface tumour antigen and the TCR-CD3 complex ${ }^{25}$. In general, ligation of CD28 without engagement of the TCR has no effect on $\mathrm{T}$ cells, defining it as a co-stimulatory receptor. However, some anti-CD28 antibodies, termed superagonist antibodies, bind to a particular epitope in
CD28 and can activate T cells without concomitant TCR engagement. The mechanism of T-cell activation by these superagonists is unclear, but involves CD28 crosslinking and might include nonspecific engagement of TCR components together with CD28 engagement through the antigen-binding site. The use of superagonist antiCD28 antibodies in vivo results in the rapid expansion of $\mathrm{T}_{\mathrm{Reg}}$ cells ${ }^{26}$, and rodent experimental data suggest they have potential for the treatment of autoimmune conditions ${ }^{27}$ and graft versus host disease ${ }^{28}$. Multiple myeloma cells also express CD28, indicating that these antibodies might prove useful for the treatment of this disease ${ }^{29}$. However, an initial clinical trial with superagonist antibodies against CD28 resulted in dramatic clinical toxicity (BOX 1).

An ex vivo application of agonist clinical-grade antihuman CD28 mAbs is the sustained expansion in culture of $\mathrm{T}$ cells for adoptive therapy ${ }^{30}$. This approach can be used for the large-scale expansion of T-cell cultures once specificity has been established by initial antigen-driven culture techniques $^{31}$.

4-1BB. The TNF receptor superfamily includes several members that deliver co-stimulatory signals to T cells $^{19,20,32}$ (FIG. 2). 4-1BB, also known as CD137, is expressed on activated $\mathrm{T}$ cells $\left(\mathrm{CD}^{+}, \mathrm{CD} 4^{+}\right.$including $\mathrm{T}_{\text {Reg }}$ cells, and NKT cells) ${ }^{33}$, cytokine-activated NK cells ${ }^{34}$, activated DCs $\mathrm{DS}^{35}$, eosinophils, mast cells and, intriguingly, endothelial cells in some metastatic tumours ${ }^{19}$. There is a single characterized ligand (4-1BBL, also known as CD137L) ${ }^{36}$ expressed on activated DCs, $B$ cells and macrophages. After binding to its ligand, $4-1 \mathrm{BB}$ delivers a co-stimulatory signal that can function independently of CD28 (REF.37). 4-1BB signalling induces the upregulation of the anti-apoptotic genes $B C L 2, B C L-X_{L}$ and BFL1, which provide protection against activation-induced T-cell death (AICD) ${ }^{19,38}$. Consistent with its function as a co-stimulator of T-cell activation, 4-1BB null mice and 4-1BBL null mice have a less robust CTL response against viruses such as lymphocytic choriomeningitis and influenza ${ }^{39,40}$. Recent evidence indicates that $4-1 \mathrm{BB}$ is required for the stable differentiation of CTLs and the establishment of long-lived memory CTLs ${ }^{41}$.

Syngeneic sarcomas, mastocytomas and lymphomas that express transfected $4-1 \mathrm{BBL}$ are rarely able to engraft in syngeneic mice. Co-expression of 4-1BBL and CD80 or CD86 in these tumours is synergistic in preventing engrafment ${ }^{42,43} \cdot 4$-1BBL-expressing tumour cells are mitogenic for pre-activated $\mathrm{CD}^{+}$and $\mathrm{CD} 4^{+} \mathrm{T}$ cells. In vitro transfection of $4-1 \mathrm{BBL}$ into $\mathrm{K} 562$ cells, which are used as artificial APCs, together with anti-CD28 mAbs improved the expansion of human T-cell cultures ${ }^{44}$. In contrast to tumour cells that expressed CD80, P815 mastocytoma and B-cell lymphoma cells that expressed $4-1 B B L$ inefficiently inhibited the growth of the corresponding untransfected tumour cells. However, a singlechain anti-4-1BB antibody anchored to the cell surface of melanoma cells functioned as a potent vaccine against untransfected mouse melanoma cells. The therapeutic efficacy of this vaccine relied mainly on the ability of NK 
Immunological synapses A supramolecular structure formed by the contacting membranes of APCs and lymphocytes that encompasses the interaction of ligandreceptor pairs, paracrine actions of cytokines, redistribution of surface molecules, intracellular signalling, reorientation of both cell cytoskeletons and the redistribution of lipid rafts.

Super-agonist mAb A stimulatory mAb for lymphocytes with effects superior to those elicited by the natural ligands (in the case of TGN 1412 this meant the induction of T-lymphocyte proliferation in the absence of antigen recognition).

\section{Activation-induced T-cell} death

Lymphocyte apoptosis to maintain lymphocyte homeostasis following T-cell activation, involving TRAIL and FASL interaction, as well as IL2, IFN $\gamma$ and the intracellular pro-apoptotic molecule BIM. It is important to contract lymphocyte numbers after the initial phase of exponential clonal expansions.

Cross presentation and cross priming

There are DCs that are able to redirect exogenous antigens to the MHC class I pathway, a phenomenon that can result either in priming (crosspriming) of a specific CTL or their tolerization depending on the maturation status of the DC. Non-migrating DCs that reside in lymphoid organs have a key role in the cross presentation of foreign antigens, suggesting an exchange of antigenic material between immigrating and resident DC subpopulations in lymph nodes.

T helper cells A differentiated class of $\mathrm{CD} 4^{+}$ T cells chiefly characterized by their ability to produce IFN $\gamma$ and their cooperative and effector roles in the cellular immune response. cells and CD4 ${ }^{+} \mathrm{T}$ cells, as their 4-1BB molecules conceivably interact with the higher affinity artificial ligand on the membrane of the melanoma cells ${ }^{45}$.

Activating (agonist) mAbs that bind 4-1BB (REF. 46) induce the complete regression of many types of established tumours derived from syngeneic mouse tumour cell lines ${ }^{47}$. This anti-tumour effect is thought to involve the activation of naive $\mathrm{T}$ cells that are specific for tumour antigens cross-presented by DCs. Therefore, circulating anti-4-1BB antibodies would co-stimulate primed $4-1 \mathrm{BB}^{+}$ $\mathrm{T}$ cells wherever they migrate throughout the body (FIG. 2). Tumour regression requires the activity of CD8 ${ }^{+}$ T lymphocytes ${ }^{47}$ and NK cells ${ }^{34}$, whereas $\mathrm{CD} 4^{+} \mathrm{T}$ cells are required in some but not all transplanted tumour models (FIG. 1). Tumour rejection is accompanied by strong CTL responses with specific cytolytic activity and interferon- $\gamma$ (IFN $\gamma$ ) secretion. Poorly immunogenic tumours that were resistant to anti-4-1BB mAbs were eradicated when combined with peptide vaccines for experimental tumour antigens such as human papillomavirus-16 E7 or tyrosinase-related protein 2 , as a result of an increased CTL response to these previously ignored antigen $s^{48}$. In this respect, vaccination with DCs pulsed with tumour lysates also resulted in the synergistic and successful treatment of two 4-1BB-mAb-resistant tumours ${ }^{49}$.

In the context of adoptive T-cell therapy, $\mathrm{T}$ cells that express $4-1 \mathrm{BB}$, and that are infused at the same time as anti-4-1BB mAbs, have a powerful synergistic effect in mice, reportedly owing to the inhibition of AICD in the adoptively transferred lymphocytes ${ }^{50}$. Treatment with anti-4-1BB also has potential in prophylactic vaccination against viral antigens from influenza and hepatitis $C$ virus ${ }^{51,52}$. Tumour antigens and viral antigens in chronic infections both induce hyporesponsiveness as a result of anergy or depletion of high-avidity-specific T cells. $4-1 \mathrm{BB} \mathrm{mAb}$ treatment has been shown to reverse tolerance of $\mathrm{CD}^{+} \mathrm{T}$ cells in tumour models ${ }^{53}$. Interestingly, it seems that $4-1 \mathrm{BB}$ ligation results in $\mathrm{CD}^{+} \mathrm{T}$ cells that have a tendency to persist as a more numerous memory-T-cell population.
Humanized anti-4-1BB mAbs have been developed (BMS-663513), and a phase I dose-escalation clinical trial in 60 patients with metastatic or locally advanced solid tumours has been initiated (National Institutes of Health Clinical trials database NCT00309023).

Paradoxically, anti-4-1BB mAbs characterized for their anti-tumour activity have been shown to prevent or ameliorate various autoimmune conditions in mice ${ }^{54}$. Furthermore, experimental evidence shows that they can suppress humoral immunity, possibly owing to interference with CD4 ${ }^{+} \mathrm{T}$ helper 1 cells ${ }^{55}$. Several mechanisms might account for these opposing effects, including increased activity of $\mathrm{T}_{\text {Reg }}$ cells, interference with $\mathrm{CD} 4^{+}$ $\mathrm{T}$-cell activation and IFN $\gamma$-dependent induction of the immunosuppressive enzyme 2,3 indoleamine dioxygenase (IDO) $)^{54}$. As a possible exception to the beneficial effects of anti-4-1BB mAb on autoimmunity, studies in mice have shown that anti-4-1BB mAbs can induce mild multifocal liver inflammatory infiltrates, although the clinical significance of this observaton is unclear ${ }^{56}$.

OX40. OX40, also known as CD134 and TNR4, is a member of the TNFR family that is expressed on activated but not resting $\mathrm{CD} 4^{+}$and $\mathrm{CD} 8^{+} \mathrm{T}$ cells ${ }^{19,20}$. Its primary role is to function as a late co-stimulatory receptor for $\mathrm{CD}^{+}$and $\mathrm{CD}^{+} \mathrm{T}$ lymphocytes ${ }^{32}$ (FIGS 1, 2). Its ligand, OX40L, is expressed on activated APCs (DC, B cells and macrophages), and might also be expressed on activated $\mathrm{T}$ cells and endothelial cells ${ }^{19}$. Ligation of OX40 co-stimulates T-cell proliferation and survival ${ }^{32}$, and although OX40 and 4-1BB seem to overlap in their intracellular signals there are differences ${ }^{57}$, possibly related to the fact that these molecules can heterodimerize on the plasma membrane ${ }^{58}$. Artificial co-stimulation of $\mathrm{CD}^{+}$and $\mathrm{CD}^{+}$ $\mathrm{T}$ cells through the activation of OX40 augments proliferation, survival and cytokine secretion. Accordingly, OX40 or OX40L deficiency in mice leads to a weaker $\mathrm{CD}^{+}$T-helper immune response $\mathrm{e}^{59,60}$.

Agonist anti-OX40 mAbs have been reported to reverse $\mathrm{CD}^{+} \mathrm{T}$-cell tolerance by overturning the

\section{Box 1 | The TGN1412 phase I clinical trial}

On 13 March 2006 the field of immunotherapy was shaken by a report of severe toxicity in a cohort of normal volunteers in a phase I dose-escalation trial testing an anti-CD28 monoclonal antibody (mAb; TGN1412) with strong 'super-agonist' effects on T lymphocytes ${ }^{126}$. Each of the first six volunteers that received the first dose (about $7 \mathrm{mg}$ ) required hospitalization for cytokine-release syndrome, including four severe cases of multiorgan failure in the context of massive angioedema and disseminated intravascular coagulation ${ }^{127}$. No fatalities occurred thanks to the instigation, albeit with several hours delay, of intensive care, steroids, plasma and a course of anti-interleukin-2 (anti-IL2) receptor antagonist mAbs. Substantial increases in the concentration of several inflammatory cytokines (tumour necrosis factor- $\alpha$, IL1 $\beta$, IL12 and IL6) were found ${ }^{127}$. Preclinical data in non-human primates given 500-fold higher doses did not forecast this adverse event, in spite of the apparent reactivity of primate CD28 with TGN1412. A thorough investigation seems to exclude misconduct, as well as production and/or quality-control pitfalls that might have explained the near fatal result (according to a report for the UK Department of Health). The outcome of the TGN1412 trial will clearly affect regulations on the clinical development of other immunostimulatory mAbs, demanding a more careful first administration to humans to minimize the risks ${ }^{128}$. In particular it will eliminate the practice of bolus administration of new mAbs to several normal volunteers with no opportunity to stop infusion when symptoms first appear ${ }^{129}$. Although immunostimulatory $\mathrm{mAbs}$ are potentially very useful agents, they require very careful preclinical and clinical testing to avoid further mishaps. It is particularly important that we do not disregard what could be a useful immune stimulant simply through lack of care or understanding in their initial testing. An important recommendation from the British investigation of the Tegenero trial is that stimulatory mAbs be first tried at very low doses. The 'low' dose in the trial is based on dilution from the highest tolerated dose in monkeys. 
anergic state induced by the exposure of $\mathrm{CD} 4^{+} \mathrm{T}$ cells to antigen (in the form of a soluble protein) under non-inflammatory conditions ${ }^{61}$. Ligation of OX40 with agonist antibodies or with an OX40L-Ig chimeric protein increases tumour immunity against various transplantable syngeneic tumours ${ }^{62,63}$. Moreover, the expression of exogenous OX40L by tumour cells increases their immunogenicity, and they are rejected through $\mathrm{CD} 4^{+}$ T helper 1 cells (Th1) and CTL responses ${ }^{64}$.

Autoimmunity as a side effect induced by OX40 stimulation has not yet been reported, although it cannot be ruled out because OX40 has been found on $\mathrm{CD} 4^{+}$lymphocytes infiltrating multiple sclerosis and inflammatory bowel disease lesions. Phase I clinical trials using a murine anti-human OX40 mAb have been initiated in patients with advanced cancer of multiple tissue origins (W. Urba, personal communication), although the ability to administer repeated doses of this xenogeneic antibody in patients will be limited owing to the immune response that will occur against the murine sequences of the antibody.

\section{MAbs that interfere with co-inhibition}

Co-inhibition can be defined as an activity mediated by cell-surface receptors that downregulate lymphocyte activation and/or effector function ${ }^{18,23}$. Intriguingly, coinhibitory receptor-ligand pairs outnumber co-stimulatory pairs in the immunoglobulin superfamily (FIG. 2), suggesting that autoimmunity and systemic inflammation were strong selective pressures during evolution. An alternative possibility, suggested by J.P. Allison, is that co-inhibitory molecules dynamically regulate the activation threshold of $\mathrm{T}$ cells to restrain $\mathrm{T}$ cells with the most avid TCRs and permit the activation of lower affinity $\mathrm{T}$ cells ${ }^{65}$. The resulting polyclonal (multi-specific) immune response would be less susceptible to failure owing to epitope loss or mutation.

CTLA-4. Cytotoxic T-lymphocyte-associated protein 4 (CTLA-4, also known as CD152) is homologous with the co-stimulatory receptor $\mathrm{CD} 28$, and they are able to bind the same ligands. However, the avidity of CTLA-4 for CD80 and CD86 is 100-1,000 times stronger than that of CD28 (REFS 18,66). CTLA-4 protein expression is induced when the TCR complex interacts with antigen and, although retained in internal vesicular T-cell compartments, emerges into the immune synapse in subsequent antigen encounters ${ }^{66}$. CTLA- 4 decreases T-cell activation, both by outcompeting CD28 for ligand binding and through the recruitment of tyrosine and serine or threonine phosphatases ${ }^{66}$. The most important molecular function of CTLA- 4 seems to be the inhibition of CD28 co-stimulation, as evidenced by the CD28-dependent ${ }^{18}$ uncontrolled lymphoproliferative and autoimmune syndrome observed in CTLA-4 null mice ${ }^{67,68}$.

Importantly, CTLA-4 is constitutively expressed on $\mathrm{CD}^{+}{ }^{+} \mathrm{CD}_{25} 5^{\text {high }}$ forkhead box $3^{+}\left(\mathrm{FOXP}^{+}\right) \mathrm{T}_{\text {Reg }}$ cells ${ }^{4}$, and it seems to function as a co-stimulator of their suppressive function in vitro. It is possible that CTLA-4 expressed by $\mathrm{T}_{\text {Reg }}$ cells is involved in inducing tolerance in CD80-expressing DCs owing to reverse signalling ${ }^{69}$. Indeed, the adoptive transfer of CTLA- 4 null T cells into normal mice does not recapitulate the autoimmune syndrome seen in the donor mice ${ }^{69}$, which suggests that CTLA-4 functions not only to regulate the activation of effector T cells, but also involves activity exerted in a dominant manner by suppressor cells ${ }^{18,70}$. However, the role of CTLA-4 in $\mathrm{T}_{\mathrm{Reg}}$ cell function remains to be definitively proven, as patients treated with anti-CTLA$4 \mathrm{mAbs}$ do not show significant changes in the number or function of circulating $\mathrm{T}_{\mathrm{Reg}}$ cells $\mathrm{s}^{71}$, although effects on $\mathrm{T}_{\mathrm{Reg}}$ cells in tumours or tissues of treated patients have not been assessed.

Monoclonal antibodies that inhibit the function of CTLA-4 (FIG. 1) are able to increase the CD8 ${ }^{+}$and $\mathrm{CD}^{+}$therapeutic immune response towards many transplantable syngeneic murine tumours with a strong therapeutic effect, although anti-tumour effects of single-agent anti-CTLA-4 mAbs are typically restricted to immunogenic tumours able to prime $\mathrm{T}$ cells ${ }^{72,70}$. The fact that CTLA- 4 is expressed only after pre-activation on effector lymphocytes explains why the in vivo effects of anti-CTLA-4 and anti-CD28 mAbs are different, although the main function of CTLA-4 seems to be the control of CD28-mediated activation ${ }^{18}$. In addition, as CTLA-4 is induced on primed cells, potential synergy with tumour vaccination seemed plausible, and although anti-CTLA-4 treatment alone had little effect on the poorly immunogenic B16 melanoma, it synergized potently with tumour cells that expressed granulocyte macrophage colony stimulating factor (GMCSF) to deplete established lesions of B16 melanoma, with concomitant autoimmune vitiligo ${ }^{73}$. Similarly, treatment with anti-CTLA-4 mAbs synergized with vaccination against a prostate-specific antigen to induce anti-tumour effects in a transgenic model of spontaneous prostate cancer (TRAMP mice), with evidence of destructive inflammation in non-malignant prostate tissue ${ }^{74}$. Synergy with synthetic peptide and DC vaccines has also been shown $n^{70,75-79}$.

The anti-tumour effects of these antibodies are probably not mediated by their effects on $\mathrm{T}_{\text {Reg }}$ cells because antiCTLA-4 mAb treatment synergizes with the depletion of $\mathrm{T}_{\mathrm{Reg}}$ cells ${ }^{80}$, and the in vivo function of $\mathrm{T}_{\mathrm{Reg}}$ cells does not seem to be downregulated by anti-CTLA- 4 treatment ${ }^{71}$. Therefore, the primary mechanism of action seems to be the prevention of CTLA-4 binding with CD80 or CD86. Murine transplantable tumour cells seem to express low levels of CD80, indicating that blocking this interaction might prevent the CD80-mediated activation of CTLA-4 on the cytotoxic T cell that has infiltrated the tumour ${ }^{81}$.

The clinical development of anti-CTLA-4 mAbs. Clinically, two different humanized monoclonal antibodies directed to human CTLA-4 are currently being independently tested in phase III clinical trials for patients with metastatic melanoma ${ }^{70}$. Both agents have shown clinical therapeutic responses, according to Response Evaluation Criteria In Solid Tumours (RECIST) criteria, some of long duration, which are uncommon in patients with advanced disease that are recruited in phase III trials. Adverse autoimmune effects have been transient and reversible. 


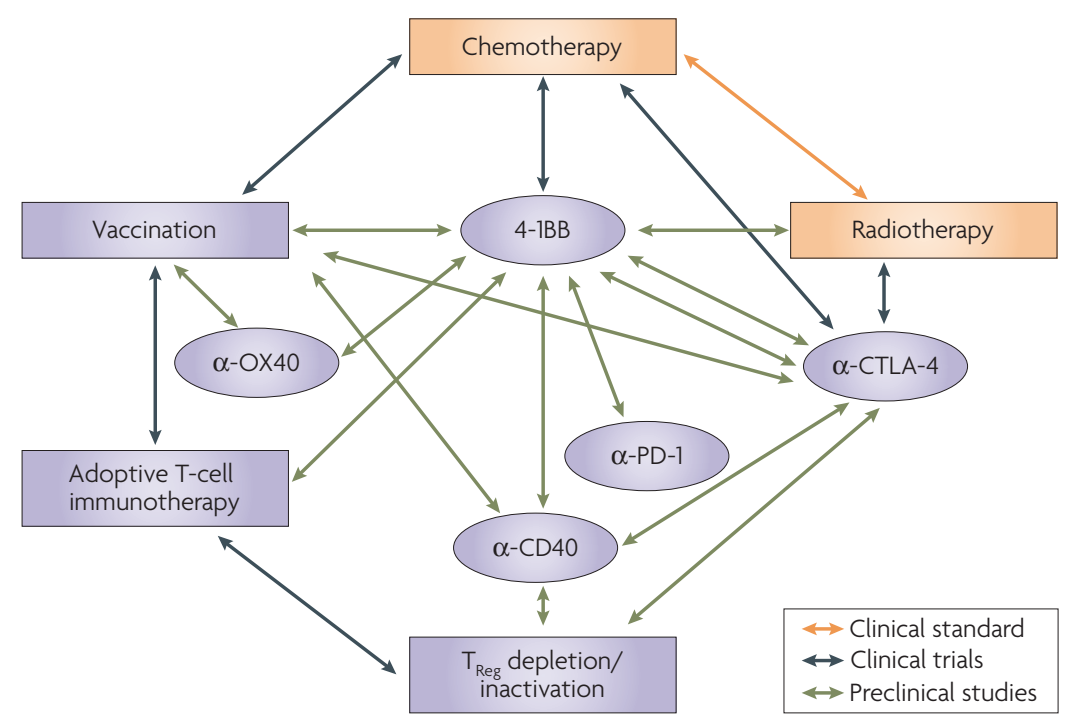

Figure 3 | Efficacious combination strategies involving immunostimulatory mAbs. A scheme of combinatorial therapeutic strategies with immunostimulatory monoclonal antibodies (mAbs) for cancer, in clinical and preclinical development. The status of each treatment or each combination (two-headed arrows) is referred to by the colour code. $\alpha$, anti.

\section{Hypopituitarism \\ The failure of the anterior lobe of the pituitary gland to sustain normal levels of the hormones that it produces. \\ Comensal flora \\ Non-pathogenic \\ microrganisms that normally \\ colonize the epithelial barriers \\ of the organism such as the \\ skin or the intestinal mucosa.}

Effector phase of CTLmediated cell killing

The killing of a target cell by an activated $\mathrm{CD} 8+\mathrm{T}$ cell that,

after antigen recognition (in close cell-cell interactions),

degranulates to release perforin and granzymes,

and expresses ligands and cytokines for death-inducing receptors on the target cell. These events have been described as the kiss of death.

\section{Clonal exhaustion}

Chronic exposure to high levels of antigen drives $\mathrm{T}$

lymphocytes into a functional state of non-responsiveness

termed 'exhaustion'. This phenomenon might have a role in impaired $\mathrm{CD} 8+\mathrm{T}$-cell response to persistent antigens. There is evidence that PD- 1 and $\mathrm{B} 7-\mathrm{H} 1$ have crucial roles in the induction and maintenance of this status.
Adverse events in the form of autoimmunity most commonly comprise pruriginous (itchy) skin eczema with generalized rashes, and inflammatory bowel syndromes with moderate to severe diarrhoea ${ }^{82}$. Pathological examination of skin and gastrointestinal lesions shows infiltrates of $\mathrm{CD} 4^{+}$and $\mathrm{CD} 8^{+} \mathrm{T}$ cells. There have been less frequent cases of inflammation of the pituitary gland (hypophysitis) causing hypopituitarism, inflammation of the uveal layer of the eye (uveitis) and hepatitis ${ }^{82-86}$. It should be noted that although these sideeffects are attributed to the induction of autoimmunity, no responses to defined auto-antigens have yet been ascertained. Therefore it is possible that some of these, particularly inflammatory bowel syndromes, could represent inappropriate responses to commensal flora. Treatment of these adverse events has required steroid therapy that conceivably counteracts the anti-tumour effects of anti-CTLA-4, albeit that there are cases of ongoing objective tumour responses during steroid therapy $^{87}$. Mitigation of autoimmune and/or hyperimmune toxicity induced by anti-CTLA-4 mAbs has also been seen in patients treated with an inhibitory anti-TNF $\alpha$ antibody (S. Rosenberg, personal communication).

The first published clinical trial of anti-CTLA$4 \mathrm{mAbs}$ involved a single dose of $3 \mathrm{mg}$ per $\mathrm{kg}$ (body weight) given to patients with melanoma or ovarian cancer. Although these were not objective responses, there were several signs of increased inflammatory responses, one of them in a cerebellar metastasis of malignant melanoma. However, this lesion became so inflamed that the patient died from intracraneal hypertension ${ }^{88}$. It was noted that the patients in this trial who had previously been treated with a DC vaccine or autologous tumour cells that express exogenous GMCSF (GVAX) had stronger pathological signs of inflammation and necrosis in their tumours ${ }^{78,88}$. A clinical trial involving 36 patients with malignant melanoma combined a bolus injection of IL2 with escalating doses of anti-CTLA-4 $\mathrm{mAb} .22 \%$ of the treated patients showed an overall response, with 3 complete responses, and there was no evidence of additive toxicity ${ }^{89}$. At present there is an extensive series of exploratory phase II clinical trials in which anti-CTLA-4 mAbs are being combined with accepted chemotherapy protocols.

The data being generated in the clinic at present involve patients with mainly malignant melanoma or renal-cell carcinoma, although there are patients with various solid tumours who have been included in various clinical trials. The results of more comprehensive trials in patients with malignant melanoma have indicated several things. First, that dosing and schedule for maximum efficacy are not established, although clinical response is rarely observed at doses less than $3 \mathrm{mg}$ per $\mathrm{kg}$ (body weight). Improved responses and increased immune toxicity are observed more frequently with multiple doses. Second, clinical responses take weeks, if not months, to occur, requiring an unusually long time window to evaluate efficacy ${ }^{85}$. Third, autoimmune reactions clearly correlate with clinical efficac ${ }^{86,87}$. Fourth, persistent immune infiltrates in lesions can last months, and therefore response criteria based only on imaging techniques might fail to fully define efficacy. Fifth, in a trial combining a previously described gp100 peptide vaccine $^{90}$, anti-CTLA- $4 \mathrm{mAb}$ did not increase the frequency of $\mathrm{T}$ cells responding to this antigen even in cases with objective responses, contrary to the expectations from mouse studies ${ }^{83,87}$. Sixth, the number and function of $\mathrm{T}_{\text {Reg }}$ cells in peripheral blood are not significantly affected in treated patients ${ }^{71}$. Seventh, there is not yet any useful immune parameter to correlate with efficacy other than tumour infiltration by immune system cells ${ }^{91}$. And last, it is still unclear whether the anti-CTLA-4 antibodies amplify a latent, weak pre-existing T-lymphocyte response or facilitate the activation of naive $\mathrm{T}$ cells. Indeed, there are no reports of the antigen specificity of $\mathrm{T}$ cells infiltrating the tumours of patients that respond to this treatment.

PD-1 and B7-H1. PD-1 (REF. 92) is another co-inhibitory receptor that shows homology with $\mathrm{CD} 28$ and whose expression is induced after activation on $\mathrm{CD}^{+}$and $\mathrm{CD}^{+} \mathrm{T}$ cells, B cells and monocytes ${ }^{16,18}$. This surface receptor has two known ligands, B7-H1 (also known as PD-L1) and B7-DC (also known as PD-L2) ${ }^{16,18}$. PD-1 ligation causes the inhibition of T-cell activation and proliferation causing cell-cycle arrest without apoptosis. The phenotype of PD-1-null mice is characterized by cell-mediated organ-specific autoimmunity ${ }^{93}$, consistent with the inhibitory function of $\mathrm{PD}-1$ in regulating TCR-CD28-dependent T-cell activation. In contrast to CTLA-4-null mice, which develop lethal multiorgan autoimmunity or hyperimmunity within 3 weeks, PD-1null mice generally develop more restricted autoimmune syndromes that are strain dependent and do not occur until beyond 6 months of age. Therefore, PD- 1 seems to be a more subtle immune checkpoint than CTLA-4. 


\section{Box 2 | Limitations in the development of immunostimulatory mAbs}

\section{Hurdles for new target identification \\ - Almost all experiments are conducted in mice, and therefore those elements of the immune system that differ between mice and humans are not easy to evaluate in experimental tumour systems. \\ - Transplantable rodent tumours are imperfect predictors of true potential effectiveness against human disease (not even in mice with spontaneous or chemically-induced tumours). \\ - Mice are imperfect predictors of toxicity for antibodies against a particular immune target. \\ - Monoclonal antibodies (mAbs) against mouse molecules are made in rats and hamsters, and therefore highly homologous proteins among rodent species are unlikely to be immunogenic for mAb production. Therefore, high-affinity antibodies against some murine targets cannot be produced. Non-biased antibody screenings with phage libraries and immunization of the corresponding knockout mice have the potential to circumvent this problem.}

Obstacles for clinical development

- Costs: the nascent field of humanized antibody technology is expensive, as it requires the bio-processing and quality control of batches of a complex tetrameric protein.

- Risks: new types of adverse effects, including autoimmune reactions and cytokine storm syndromes, might be associated with the use of these mAbs.

- Combination regimens will probably be needed to achieve clinically meaningful efficacy.

- Difficulties in the development of reliable immunoassays as surrogate endpoints for biological activity.

- Complex intellectual property issues involving different owners, that ultimately require complex business arrangements and possibly initiatives from national or supranational funding agencies ${ }^{130}$.

\section{Waldenström}

macroglobulinaemia

A haematological malignancy resulting from the

transformation of plasma cells that produce a multimeric IgM.

\section{DC maturation}

The phenotypic changes experienced by DCs that

increase the expression of

$T$ cell co-stimulatory

molecules, levels of antigen

presentation and the

production of T-cell stimulatory

cytokines (IL12, IL2, IL23,

IL15 and IFN $\gamma$.

Plasmacytoid DCs

A subpopulation of leukocytes that produce high amounts of

type I IFN when detecting viral substances. Recently its expression of $\mathrm{CD} 40$ ligand seems to be important for activating conventional myeloid DCs. Their in vivo role in antigen presentation is not known.
B7-H1 expression has been described on various human tumour cells ${ }^{94}$, and expression of this molecule decreases the immunogenicity of mouse tumours in vivo ${ }^{94}$. In addition, the expression of $\mathrm{B} 7-\mathrm{H} 1$ in human malignancies correlates with a poor prognosis ${ }^{95}$.

B7-DC can deliver co-stimulatory or co-inhibitory signals to primed lymphocytes, depending on the culture conditions ${ }^{96,97}$. Its expression is restricted to activated DCs, and it is thought to induce T-cell co-stimulation through an as-yet unidentified counter receptor expressed on activated T cells.

The administration of mAbs against PD- 1 and B7$\mathrm{H} 1$ has produced CTL-mediated anti-tumour effects in mice ${ }^{98}$. B7-H1 interferes with the effector phase of CTL-mediated cell killing ${ }^{98}$ (FIG. 1). Interest in this target is fuelled by the finding that mice chronically infected with lymphocytic choriomeningitis show clonal exhaustion in $\mathrm{CD} 8^{+}$CTLs that recognize the viral antigens. The exhausted clones expressed high levels of PD-1, and the blockade of both PD-1 and B7-H1 with mAbs reversed this phenotype in vivo, and the mice regained T-cell mediated anti-viral activity ${ }^{99}$. No data have been reported so far on the reversion of clonal exhaustion in $\mathrm{T}$ cells in tumour-bearing mice. Phase I clinical trials have been initiated in cancer patients with a fully human anti-PD-1 mAb, although there is not yet evidence for clonal exhaustion accounting for weak $\mathrm{T}$-cell responses towards human malignancies.
A divergent line of research has found that a multivalent human IgM $\mathrm{mAb}$ directed against $\mathrm{B} 7-\mathrm{DC}$ from the serum of a patient with Waldenström macroglobulinaemia delivers a strong DC maturation signal after B7-DC crosslinking (FIG. 1), inducing the secretion of IL12 from $\mathrm{DCs}^{100}$. Giving this $\mathrm{mAb}$ to mice induces T-cell-dependent rejection of transplantable tumours, and so indicates clinical potential ${ }^{101}$.

\section{MAbs that improve the performance of APCs}

Mature or activated DCs are capable of inducing potent T-cell clonal expansion and effector differentiation ${ }^{7}$. DC maturation ${ }^{102}$ causes the upregulation of co-stimulatory molecules such as CD80 and CD86 and cytokines (such as IL2, IL12, IL15, IL23, IFN $\alpha$, IFN $\beta$ and IFN $\gamma$ ) that drive full effector differentiation of $\mathrm{T}$ and NK cells. However, under steady-state conditions antigen presentation by incompletely activated DCs causes T-cell anergy or depletion after an abortive transient activation. Incompletely activated DCs are evident in patients with cancer?

CD40. The constitutive expression of CD40 is crucial for the function of $B$ cells and DCs ${ }^{103}$. This molecule belongs to the TNFR superfamily. CD40 expression is not restricted to B cells and DCs, but is also expressed on macrophages, $\mathrm{T}$ cells and in non-haemopoietic tissue such as vascular endothelium and multiple epithelia. In fact, CD40 is often expressed on the surface of carcinoma and lymphoma cells. There is a single ligand, CD40L, which is chiefly expressed on activated Thelper cells ${ }^{103,104}$, although it can also be expressed on activated NK cells, platelets and plasmacytoid DCs. In the immune system CD40 ligation is crucial for a competent cellular immune response, as well as for affinity maturation and heavy chain class switching in the humoral immune response. These functions of the CD40L-CD40 system are supported by the humoral and cellular immunodeficiency observed in humans with mutations in CD40L or CD40, and mice in which the genes that encode these proteins are knocked out. CD40 seems crucial to the licensing of DCs, and enables them to drive effector CTL responses, in part through the induction of IL12 secretion by DCs ${ }^{105,106}$.

MAbs specific for CD40 can exert two types of antitumour effects. Some of them are conceivably exerted on CD40-expressing tumour cells by mediating antibodydependent cellular cytotoxicity (ADCC) or complementdependent cytotoxicity ${ }^{104}$. In addition, CD40 signalling in some carcinomas and lymphomas can promote tumour cell apoptosis ${ }^{104}$.

However, it has been observed in many preclinical models that the anti-tumour effects of CD40 ligation by $\mathrm{mAbs}$ require a functional immune system ${ }^{107}$. Proposed mechanisms involve the activation of DCs and possibly, in the case of lymphoma, the conversion of malignant B cells into efficient APCs for CTL induction. It is clear that triggering CD40 can at least partially overcome the need for T-cell help and enable efficient, long lasting anti-tumour immunity as experimentally observed following $\mathrm{CD} 4^{+} \mathrm{T}$-cell depletion ${ }^{108,109}$. Both anti-CD40 


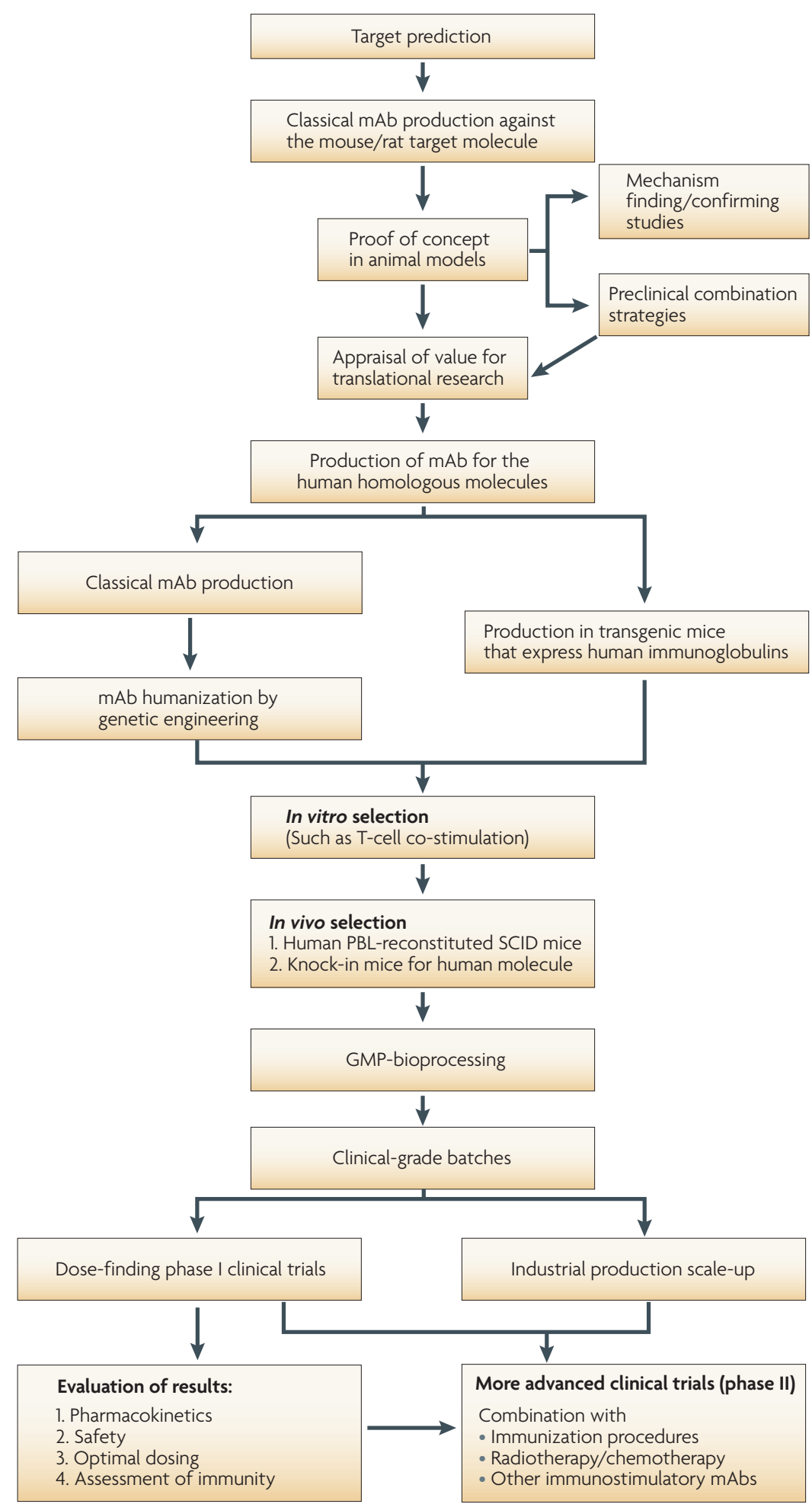

Figure 4 | Route from preclinical to clinical development of immunostimulatory monoclonal antibodies. A flow chart of the discovery and development paths, depicting the progression of an immunostimulatory monoclonal antibody (mAb) towards the clinic: from target identification to clinical trials (Supplementary information S2 (box)). It should be kept in mind that immunostimulatory mAbs, at least in some instances, challenge commonly accepted paradigms for small-molecule development in cancer because they often have no clear dose-response effects, the late onset of beneficial effects in some cases, inconsistency in the evaluation of response by standard imaging techniques, immunological tests that measure anti-tumour immunity as a surrogate endpoint and, above all, new types of adverse effects.
$\mathrm{mAb}$ and CD40L have also been used to mature cultured DCs in vitro before use in DC vaccines ${ }^{108}$, and some DCs have been transfected with CD40L before use $^{110}$. In fact, early clinical work adopted a modified version of this strategy with the direct expression of CD40L in chronic lymphocytic leukaemia cells using a recombinant adenovirus vector. An increase in the number of anti-tumour T cells, and a decrease in the number of circulating malignant lymphocytes and in the size of the involved lymph nodes were seen in patients who were infused with chronic lymphocytic leukaemia cells expressing CD40L ${ }^{111}$.

The first clinical trial to investigate the use of a soluble CD40 trigger used a recombinant human CD40L trimer, rhuCD40L, which has potent agonistic activity ${ }^{112}$. Thirtytwo patients with either solid tumours or non-Hodgkin lymphoma were given a 5-day course of between 0.05 and $0.15 \mathrm{mg}$ per $\mathrm{kg}$ (body weight) in a dose-escalation study. The maximum tolerated dose (MTD) was $0.1 \mathrm{mg}$ per $\mathrm{kg}$ (body weight) a day based on transient increases of liver transaminases in the serum. Despite this relatively small dose, two responses were recorded, one complete and one partial, and 12 patients achieved benefit in terms of some degree of stable disease. The complete response was particularly interesting because it occured a long time after the treatment was given. More recently, Seattle Genetics has investigated the use of a humanized anti-CD40 $\mathrm{mAb}(\mathrm{SGN}-40)$ in a phase I dose-escalation study ${ }^{113}$. Thirty-five patients, 23 with multiple myeloma and 12 with non-Hodgkin lymphoma, were treated with weekly doses of between 2 and 4 mg per kg (body weight). SGN40 was surprisingly well tolerated compared with other studies that have used CD40L or anti-CD40 mAbs, with no serious adverse events reported. Two patients, both with non-Hodgkin lymphoma, achieved a partial response, one of which was sustained for several months. In addition, although the criteria for an objective response were not met, a decrease in the level of the monoclonal (M)-protein produced by the malignant myeloma cells was recorded in four patients, indicating a decrease in tumour burden.

Finally, Vonderheide and colleagues have recently reported a phase I clinical trial using a different anti-CD40 $\mathrm{mAb}$ in various types of tumour. This is a fully human IgG2 agonistic mAb, CP-870,893 (REF. 114). Interestingly, there were four partial responses observed in patients with malignant melanoma, but dose-limiting toxicity was seen at low doses such as $0.3 \mathrm{mg}$ per $\mathrm{kg}$ (body weight) owing to systemic inflammatory syndromes ${ }^{115}$. At present there are ongoing phase I trials with two unrelated human antiCD40 mAbs in patients with non-Hodgkin lymphoma, chronic lymphocytic leukaemia or multiple myeloma.

Therapeutic combinations to increase efficacy Stepwise clinical development requires early clinical trials to test new agents as monotherapies. However, it is thought that combination therapies have the potential to establish synergistic anti-tumour activity (FIG. 3). Anti-CTLA-4 mAbs have shown preclinical synergistic effects with several forms of cancer vaccines, as well as with radiotherapy ${ }^{116}$ and chemotherapy ${ }^{117}$. There 
is a conspicuous lack of experimental information on whether anti-CTLA-4 mAbs also safely increase the efficacy of adoptive T-cell transfer in mouse models.

Interestingly, it has recently been reported that there is a synergistic effect of co-administration of anti-4-1BB and anti-CTLA-4 mAbs ${ }^{56}$. Experiments in human CTLA-4 knock-in mice permitted these observations to be made with the human anti-CTLA- $4 \mathrm{mAb}^{56}$, but only in the MC38 colon carcinoma model, and not with other less immunogenic tumours such as B16 melanoma. Importantly, co-administration with anti-4-1BB mAbs seemed to ameliorate the autoimmune infiltrates that are elicited by anti-CTLA- 4 mAb treatment ${ }^{56}$.

Anti-CTLA-4 mAbs can synergize with anti-CD40 $\mathrm{mAbs}$ and the depletion of $\mathrm{T}_{\mathrm{Reg}}$ cells in a preclinical mode ${ }^{80}$. When thinking about combining treatments with anti-CTLA-4 mAbs one has to be mindful that the simultaneous or sequential manipulation of various check points of immune regulation could trigger untreatable autoimmunity, as a result of simultaneously loosening too many immunological 'brakes'.

4-1BB mAbs have also shown increased efficacy in preclinical models when combined with chemotherapy ${ }^{118}$. A clinical trial has recently been approved to test chemotherapy plus anti-4-1BB mAbs in ovarian cancer (NCT00351325). Tumour antigen vaccines are synergistic with anti-4-1BB mAbs and as adoptive T-cell therapy ${ }^{50}$. Synergy with DC-vaccination seems highly effective and has been observed with tumour lysate-loaded $\mathrm{DCs}^{49}$ and intratumoral injection of DCs genetically engineered to produce IL12 (REF. 119).

A very encouraging recent study documented unprecedented efficacy in mice treated with a combination of anti-CD40 and anti-4-1BB mAbs ${ }^{120}$. Interestingly, the activity was increased with $\mathrm{mAb}$ raised against death receptor 5 (DR5), a member of the TNFR superfamily that induces the apoptosis of tumour cells ${ }^{120}$. Efficacy was remarkable even against autochthonous sarcomas induced by a chemical carcinogen. The induction of tumour cell death by anti-DR5 antibodies concomitant with immunostimulatory mAbs suggested that tumour apoptosis mediates the release of tumour antigens for cross-presentation by DCs, and might favour T-cell infiltration in tumour lesions. Other approaches that adopt similar combinations to cause local tumour cell destruction should be explored. Treatment with 4-1BB agonist mAbs (and to a lesser extent with cells expressing 4-IBBL) synergizes with IL12 gene transfer in tumour cells to mediate tumour clearence in mice ${ }^{121,122}$.

Another interesting area still largely unexplored is the combination of an immunostimulatory mAb with allogeneic or autologous bone-marrow transplantation. It has been reported that anti-4-1BB mAbs increase both acute graft versus host disease and its linked graft versus leukaemia effect in mice ${ }^{123}$, whereas anti-4-1BB mAb ameliorates chronic graft versus host disease ${ }^{124}$.

Anti-OX40 mAbs potently synergize with anti4-1BB mAbs in murine-tumour and viral-infection models, without apparent side effects ${ }^{63}$. Further benefit was apparent when the tumour cells expressed exogenous IL12 (REF. 63). If given alongside vaccination this combination can successfully treat breast carcinoma developing in mouse-mammary tumour (MMTV)-neu transgenic mice ${ }^{125}$.

Anti-PD-1 and anti-B7-H1 mAbs show synergistic therapeutic effects with agonist anti-4-1BB mAbs against tumour cells that express B7-H1 as an immune-escape mechanism ${ }^{98}$. Identification of primary immune-escape mechanisms for particular classes of tumour could be important in the future to tailor the most suitable combinations on an individual basis.

Developing new immunostimulatory mAbs that target recently identified co-stimulatory and co-inhibitory molecules (Supplementary information S1 (box)) is an exciting but challenging area of translational and reverse-translational research (BOX 2). It is important that any new immunostimulatory compound is tested thoroughly and systematically in a stepwise manner (FIG. 4 and Supplementary information S2 (box)). Perhaps the most promising observations are those that indicate that therapies that include immunostimulatory mAbs seem to have a synergistic effect (FIG. 3). phagocytosis or cause osmotic cell lysis to form

transmembrane pores.
10. Gattinoni, L., Powell, D. J. Jr, Rosenberg, S. A. \& Restifo, N. P. Adoptive immunotherapy for cancer: building on success. Nature Rev. Immunol. 6 , 383-393 (2006).

11. Imai, K. \& Takaoka, A. Comparing antibody and smallmolecule therapies for cancer. Nature Rev. Cancer 6 , 714-727 (2006).

12. Winter, G. \& Harris, W. J. Humanized antibodies. Immunol. Today 14, 243-246 (1993).

13. Jakobovits, A. et al. Production of antigen-specific human antibodies from mice engineered with human heavy and light chain YACs. Ann. NY Acad. Sci. 764 , 525-535 (1995).

14. Fishwild, D. M. et al. High-avidity human IgG kappa monoclonal antibodies from a novel strain of minilocus transgenic mice. Nature Biotechnol. 14, 845-851 (1996).

15. Murillo, O. et al. Potentiation of therapeutic immune responses against malignancies with monoclonal antibodies. Clin. Cancer Res. 9, 5454-5464 (2003)

16. Chen, L. Co-inhibitory molecules of the B7-CD28 family in the control of T-cell immunity. Nature Rev. Immunol. 4, 336-347 (2004).

17. Bromley, S. K. et al. The immunological synapse. Annu. Rev. Immunol. 19, 375-396 (2001).
18. Greenwald, R. J., Freeman, G. J. \& Sharpe, A. H. The B7 family revisited. Annu. Rev. Immunol. 23, 515-548 (2005)

19. Watts, T. H. TNF/TNFR family members in costimulation of T cell responses. Annu. Rev. Immunol. 23, 23-68 (2005).

20. Croft, M. Co-stimulatory members of the TNFR family: keys to effective T-cell immunity? Nature Rev. Immunol. 3, 609-620 (2003).

21. Acuto, O. \& Michel, F. CD28-mediated co-stimulation: a quantitative support for TCR signalling. Nature Rev. Immunol. 3, 939-951 (2003).

22. Alegre, M. L., Frauwirth, K. A. \& Thompson, C. B. T-cell regulation by $\mathrm{CD} 28$ and $\mathrm{CTLA}-4$. Nature Rev. Immunol. 1, 220-228 (2001).

23. Chen, L. et al. Costimulation of antitumor immunity by the B7 counterreceptor for the T lymphocyte molecules CD28 and CTLA-4. Cell 71, 1093-1102 (1992).

24. Townsend, S. E. \& Allison, J. P. Tumor rejection after direct costimulation of $\mathrm{CD} 8{ }^{+} \mathrm{T}$ cells by $\mathrm{B} 7$-transfected melanoma cells. Science 259, 368-370 (1993).

25. Cochlovius, B. et al. Cure of Burkitt's lymphoma in severe combined immunodeficiency mice by T cells, tetravalent CD3 x CD19 tandem diabody, and CD28 costimulation. Cancer Res. 60, 4336-4341 (2000). 
26. Lin, C. H. \& Hunig, T. Efficient expansion of regulatory $\mathrm{T}$ cells in vitro and in vivo with a CD28 superagonist. Eur. J. Immunol. 33, 626-638 (2003).

27. Beyersdorf, N. et al. Selective targeting of regulatory T cells with $\mathrm{CD} 28$ superagonists allows effective therapy of experimental autoimmune encephalomyelitis. J. Exp. Med. 202, 445-455 (2005).

28. Albert, M. H., Yu, X. Z., Martin, P. J. \& Anasetti, C. Prevention of lethal acute GVHD with an agonistic CD28 antibody and rapamycin. Blood 105 . 1355-1361 (2005).

29. Qiu, Y. H. et al. Apoptosis of multiple myeloma cells induced by agonist monoclonal antibody against human CD28. Cell Immunol. 236, 154-160 (2005).

30. Rapoport, A. P. et al. Restoration of immunity in lymphopenic individuals with cancer by vaccination and adoptive T-cell transfer. Nature Med. 11 1230-1237 (2005).

31. Porter, D. L. et al. A phase 1 trial of donor lymphocyte infusions expanded and activated ex vivo via CD3/ CD28 costimulation. Blood 107, 1325-1331 (2006).

32. Croft, M. Costimulation of T cells by OX40, 4-1BB, and CD27. Cytokine Growth Factor Rev. 14, 265-273 (2003).

33. Pollok, K. E. et al. Inducible T cell antigen 4-1BB Analysis of expression and function. J. Immunol. 150, 771-781 (1993)

34. Melero, I., Johnston, J. V., Shufford, W. W., Mittler, R. S. \& Chen, L. NK1. 1 cells express 4-1BB (CDw137) costimulatory molecule and are required for tumor immunity elicited by anti-4-1BB monoclonal antibodies. Cell Immunol. 190, 167-172 (1998).

35. Wilcox, R. A. et al. Cutting edge: Expression of functional $C D 137$ receptor by dendritic cells. J. Immunol. 168, 4262-4267 (2002).

36. Goodwin, R. G. et al. Molecular cloning of a ligand for the inducible $\mathrm{T}$ cell gene 4-1BB: a member of an emerging family of cytokines with homology to tumor necrosis factor. Eur. J. Immunol. 23, 2631-2641 (1993).

37. Saoulli, K. et al. CD28-independent, TRAF2 dependent costimulation of resting $T$ cells by $4-1 \mathrm{BB}$ ligand. J. Exp. Med. 187, 1849-1862 (1998).

38. Takahashi, C., Mittler, R. S. \& Vella, A. T. Cutting edge: $4-1 \mathrm{BB}$ is a bona fide CD8 T cell survival signal. J. Immunol. 162, 5037-5040 (1999).

39. Kwon, B. S. et al. Immune responses in 4-1BB (CD 137)deficient mice. J. Immunol. 168, 5483-5490 (2002).

40 DeBenedette, M. A et al. Analysis of 4-1BB ligand (4-1BBL)-deficient mice and of mice lacking both 4-1BBL and CD28 reveals a role for 4-1BBL in skin allograft rejection and in the cytotoxic $T$ cell response to influenza virus. J. Immunol. 163, 4833-4841 (1999).

41. Myers, L. et al. Combined CD137 (4-1BB) and adjuvant therapy generates a developing pool of peptide-specific CD8 memory T cells. Int. Immunol. 18, 325-333 (2006)

42. Melero, I. et al. Amplification of tumor immunity by gene transfer of the co-stimulatory 4-1BB ligand synergy with the CD28 co-stimulatory pathway. Eur. $J$. Immunol. 28, 1116-1121 (1998).

43. Guinn, B. A., DeBenedette, M. A., Watts, T. H. \& Berinstein, N. L. 4-1BBL cooperates with B7-1 and B7-2 in converting a B cell lymphoma cell line into a long-lasting antitumor vaccine. J. Immunol. 162, 5003-5010 (1999).

44. Maus, M. V. et al. Ex vivo expansion of polyclonal and antigen-specific cytotoxic T lymphocytes by artificial APCs expressing ligands for the T-cell receptor, CD28 and 4-1BB. Nature Biotechnol. 20, 143-148 (2002)

45. Ye, Z. et al. Gene therapy for cancer using single-chain Fv fragments specific for 4-1BB. Nature Med. 8, 343-348 (2002)

46. Shuford, W. W. et al. 4-1BB costimulatory signals preferentially induce $\mathrm{CD} 8{ }^{+} \mathrm{T}$ cell proliferation and lead to the amplification in vivo of cytotoxic $\mathrm{T}$ cell responses. J. Exp. Med. 186, 47-55 (1997).

47. Melero, l. et al. Monoclonal antibodies against the 4-1BB T-cell activation molecule eradicate established tumors. Nature Med. 3, 682-685 (1997)

The first description of the anti-tumour effects of anti-4-1BB mAbs in mouse tumour models and the requirement of the immune system. The potency of the therapeutic effects of the mAbs supports ongoing clinical trials with a similar strategy.

48. Wilcox, R. A. et al. Provision of antigen and CD 137 signaling breaks immunological ignorance, promoting regression of poorly immunogenic tumors. J. Clin. Invest. 109, 651-659 (2002).
An in vivo study in mice that explores the combination of peptide immunization plus the systemic supply of co-stimulation with anti-4-1 BB mAbs. The authors correlate efficacy with the generation of an anti-tumour CTL response. Together with reference 73 this article supports the idea of combining immunization and/or priming against tumour antigens with mmunostimulatory mAbs.

49. Ito, F. et al. Anti-CD137 monoclonal antibody administration augments the antitumor efficacy of dendritic cell-based vaccines. Cancer Res. 64 , 8411-8419 (2004)

50. May, K. F. Jr, Chen, L., Zheng, P. \& Liu, Y. Anti-4-1BB monoclonal antibody enhances rejection of large tumor burden by promoting survival but not clonal expansion of tumor-specific CD8 ${ }^{+} \mathrm{T}$ cells. Cancer Res. 62, 3459-3465 (2002)

51. Halstead, E. S., Mueller, Y. M., Altman, J. D. \& Katsikis, P. D. In vivo stimulation of CD 137 broadens primary antiviral $\mathrm{CD}^{+} \mathrm{T}$ cell responses. Nature Immunol. 3, 536-541 (2002).

52. Arribillaga, L. et al. Enhancement of CD4 and CD8 immunity by anti-CD137 (4-1BB) monoclonal antibodies during hepatitis $C$ vaccination with recombinant adenovirus. Vaccine 23, 3493-3499 (2005)

53. Wilcox, R. A. et al. Ligation of $\mathrm{CD} 137$ receptor prevents and reverses established anergy of CD8 ${ }^{+}$cytolytic $T$ lymphocytes in vivo. Blood 103, 177-184 (2004).

54. Myers, L. M. \& Vella, A. T. Interfacing T-cell effecto and regulatory function through CD 137 (4-1BB) co-stimulation. Trends Immunol. 26, 440-446 (2005)

55. Mittler, R S Bailey, T S , Klussman, K. Trailsmith, M. D. \& Hoffmann, M. K. Anti-4-1BB monoclonal antibodies abrogate $\mathrm{T}$ cell-dependent humoral immune responses in vivo through the induction of helper T cell anergy. J. Exp. Med. 190 1535-1540 (1999).

56. Kocak, E. et al. Combination therapy with anti-CTL antigen-4 and anti-4-1BB antibodies enhances cancer immunity and reduces autoimmunity. Cancer Res. 66, 7276-7284 (2006).

This article provides two important points. First, it provides evidence of the synergistic combination of anti-4-1BB and anti-CD40 mAbs with an amelioration of the autoimmune effects induced by anti-CTLA-4 mAbs. Second, these results are reproducible with antibodies to the human version of CTLA-4 in knock-in mice for this molecule.

57. Lee, S. W. et al. Functional dichotomy between OX40 and $4-1 \mathrm{BB}$ in modulating effector CD8 T cell responses. J. Immunol. 177, 4464-4472 (2006)

58. Ma, B. Y. et al. The expression and the regulatory role of OX40 and 4-1BB heterodimer in activated human T cells. Blood 106, 2002-2010 (2005).

59. Kopf, M. et al. OX40-deficient mice are defective in Th cell proliferation but are competent in generating $B$ cell and CTL Responses after virus infection. Immunity 11, 699-708 (1999)

60. Murata, K. et al. Impairment of antigen-presenting cell function in mice lacking expression of OX40 ligand. J. Exp. Med. 191, 365-374 (2000).

61. Bansal-Pakala, P., Jember, A. G. \& Croft, M. Signaling through OX40 (CD 134) breaks peripheral T-cell tolerance. Nature Med. 7, 907-912 (2001)

62. Weinberg, A. D. et al. Engagement of the OX-40 receptor in vivo enhances antitumor immunity. J. Immunol. 164, 2160-2169 (2000). Shows that systemic OX40 ligation increases tumour immunity, with a role for $\mathrm{CD}^{+}{ }^{+}$cells in the difficult-to-treat B16 melanoma model. This evidence supports ongoing clinical trials and has raised interest in this co-stimulatory target.

63. Pan, P. Y., Zang, Y., Weber, K., Meseck, M. L. \& Chen, S. H. OX40 ligation enhances primary and memory cytotoxic T lymphocyte responses in an

immunotherapy for hepatic colon metastases. $\mathrm{Mol}$. Ther. 6, 528-536 (2002).

64. Andarini, S. et al. Adenovirus vector-mediated in vivo gene transfer of OX40 ligand to tumor cells enhance antitumor immunity of tumor-bearing hosts. Cancer Res. 64, 3281-3287 (2004).

65. Egen, J. G. \& Allison, J. P. Cytotoxic T lymphocyte antigen- 4 accumulation in the immunological synapse is regulated by TCR signal strength. Immunity 16 , 23-35 (2002).

66. Teft, W. A Kirchhof, M. G. \& Madrenas, J. A molecular perspective of CTLA-4 function. Annu. Rev. Immunol. 24, 65-97 (2006).
67. Tivol, E. A et al. Loss of CTLA-4 leads to massive lymphoproliferation and fatal multiorgan tissue destruction, revealing a critical negative regulatory role of CTLA-4. Immunity 3, 541-547 (1995).

68. Waterhouse, P. et al. Lymphoproliferative disorders with early lethality in mice deficient in Ctla-4. Science 270, 985-988 (1995).

69. Fallarino, F. et al. Modulation of tryptophan catabolism by regulatory T cells. Nature Immunol. 4, 1206-1212 (2003)

70. Korman, A. J., Peggs, K. S. \& Allison, J. P. Checkpoint blockade in cancer immunotherapy. Adv. Immunol. 90 297-339 (2006)

71. Maker, A. V., Attia, P. \& Rosenberg, S. A. Analysis of the cellular mechanism of antitumor responses and autoimmunity in patients treated with CTLA-4 blockade. J. Immunol. 175, 7746-7754 (2005).

72. Leach, D. R., Krummel, M. F. \& Allison, J. P. Enhancement of antitumor immunity by CTLA-4 blockade. Science 271, 1734-1736 (1996). A seminal paper in the field of immunostimulatory monoclonal antibodies in which the authors showed anti-tumour effects following injections of mAbs that antagonize CTLA-4 function in mice harbouring a transplantable colon cancer. It was correctly interpreted that the mechanism of action relied on the neutralization of the inhibitory functions of CTLA-4.

73. van Elsas, A., Hurwitz, A. A. \& Allison, J. P. Combination immunotherapy of B16 melanoma using anti-cytotoxic T lymphocyte-associated antigen 4 (CTLA-4) and granulocyte/macrophage colonystimulating factor (GM-CSF)-producing vaccines induces rejection of subcutaneous and metastatic tumors accompanied by autoimmune

depigmentation. J. Exp. Med. 190, 355-366 (1999).

This paper showed for the first time that the antitumour effects of anti-CTLA-4 mAbs were synergistically augmented with vaccination against tumour cells and, together with reference 48 , provides the rationale for combining tumour vaccines and immunostimulatory $\mathrm{mAbs}$.

74. Hurwitz, A. A. et al. Combination immunotherapy of primary prostate cancer in a transgenic mouse model using CTLA-4 blockade. Cancer Res. 60, 2444-2448 (2000).

75. Ito, D., Ogasawara, K., Iwabuchi, K., Inuyama, Y. \& Onoe, K. Induction of CTL responses by simultaneous administration of liposomal peptide vaccine with antiCD40 and anti-CTLA-4 mAb. J. Immunol. 164, 1230-1235 (2000).

76. Pedersen, A. E., Buus, S. \& Claesson, M. H. Treatment of transplanted CT26 tumour with dendritic cell vaccine in combination with blockade of vascular endothelial growth factor receptor 2 and CTLA-4. Cancer Lett. 235, 229-238 (2006).

77. Keler, T. et al. Activity and safety of CTLA-4 blockade combined with vaccines in cynomolgus macaques. J. Immunol. 171, 6251-6259 (2003).

78. Hodi, F. S. \& Dranoff, G. Combinatorial cancer immunotherapy. Adv. Immunol. 90, 341-368 (2006).

79. Ribas, A. et al. Role of dendritic cell phenotype, determinant spreading, and negative costimulatory blockade in dendritic cell-based melanoma immunotherapy. J. Immunother. 27, 354-367 (2004).

80. Sutmuller, R. P. et al. Synergism of cytotoxic T lymphocyte-associated antigen 4 blockade and depletion of $\mathrm{CD} 25(+)$ regulatory T cells in antitumor therapy reveals alternative pathways for suppression of autoreactive cytotoxic T lymphocyte responses. J. Exp. Med. 194, 823-832 (2001).

81. Tirapu, I. et al. Low surface expression of B7-1 (CD80) is an immunoescape mechanism of colon carcinoma. Cancer Res. 66, 2442-2450 (2006).

82. Blansfield, J. A. et al. Cytotoxic T-lymphocyteassociated antigen-4 blockage can induce autoimmune hypophysitis in patients with metastatic melanoma and renal cancer. J. Immunother. $\mathbf{2 8}$, 593-598 (2005)

83. Phan, G. Q. et al. Cancer regression and autoimmunity induced by cytotoxic $\mathrm{T}$ lymphocyte-associated antige 4 blockade in patients with metastatic melanoma. Proc. Natl Acad. Sci. USA 100, 8372-8377 (2003). A pioneering paper (along with reference 88 ) showing the anti-tumour activity of the infusion of anti-CTLA-4 mAbs in humans. This paper provided the basis for subsequent clinical trials and identified reversible organ-specific autoimmunity as a common side effect. 
84. Robinson, M. R. et al. Cytotoxic T lymphocyteassociated antigen 4 blockade in patients with metastatic melanoma: a new cause of uveitis. J. Immunother. 27, 478-479 (2004).

85. Ribas, A. et al. Antitumor activity in melanoma and anti-self responses in a phase I trial with the anticytotoxic T lymphocyte-associated antigen 4 monoclonal antibody CP-675, 206. J. Clin. Oncol. 23, 8968-8977 (2005)

86. Sanderson, K. et al. Autoimmunity in a phase I trial of a fully human anti-cytotoxic T-lymphocyte antigen-4 monoclonal antibody with multiple melanoma peptides and Montanide ISA 51 for patients with resected stages III and IV melanoma. J. Clin. Oncol. 23, 741-750 (2005).

87. Attia, P. et al. Autoimmunity correlates with tumor regression in patients with metastatic melanoma treated with anti-cytotoxic T-lymphocyte antigen-4. J. Clin. Oncol. 23, 6043-6053 (2005).

88. Hodi, F. S et al. Biologic activity of cytotoxic T lymphocyte-associated antigen 4 antibody blockade in previously vaccinated metastatic melanoma and ovarian carcinoma patients. Proc. Natl Acad. Sci. USA 100, 4712-4717 (2003).

The first paper to show clinically meaningful biological effects of an anti-CTLA-4 mAb in human and describe indications of efficacy. It is the first report published in a journal on the effects of an anti-CTLA-4 mAb in humans.

89. Maker, A. V. et al. Tumor regression and autoimmunity in patients treated with cytotoxic T lymphocyteassociated antigen 4 blockade and interleukin 2: a phase I/ll study. Ann. Surg. Oncol. 12, 1005-1016 (2005).

90. Rosenberg, S. A. et al. Immunologic and therapeutic evaluation of a synthetic peptide vaccine for the treatment of patients with metastatic melanoma. Nature Med. 4, 321-327 (1998)

91. Reuben, J. M. et al. Biologic and immunomodulatory events after CTLA-4 blockade with ticilimumab in patients with advanced malignant melanoma. Cancer 106, 2437-2444 (2006)

92. Ishida, Y., Agata, Y., Shibahara, K. \& Honjo, T. Induced expression of PD-1, a novel member of the immunoglobulin gene superfamily, upon programmed cell death. EMBO J. 11, 3887-3895 (1992)

93. Nishimura, H. et al. Autoimmune dilated cardiomyopathy in PD-1 receptor-deficient mice. Science 291, 319-322 (2001)

94 Dong, $\mathrm{H}$. et al. Tumor-associated $\mathrm{B} 7-\mathrm{H} 1$ promotes T-cell apoptosis: a potential mechanism of immune evasion. Nature Med. 8, 793-800 (2002). This paper provides mechanistic evidence for a role of the PD-1-B7-H1 ligand-receptor pair in tumour evasion from the immune response. It provides evidence to suggest that blocking this interaction with a mAb could potentially increase anti-tumour immunity.

95. Thompson, R. H. et al. Tumor B7-H1 is associated with poor prognosis in renal cell carcinoma patients with long-term follow-up. Cancer Res. 66, 3381-3385 (2006).

96. Tseng, S. Y. et al. B7-DC, a new dendritic cell molecule with potent costimulatory properties for $\mathrm{T}$ cells. J. Exp. Med. 193, 839-846 (2001).

97. Latchman, Y. et al. PD-L2 is a second ligand for PD-1 and inhibits T cell activation. Nature Immunol. 2, 261-268 (2001)

98. Hirano, F. et al. Blockade of B7-H1 and PD-1 by monoclonal antibodies potentiates cancer therapeutic immunity. Cancer Res. 65, 1089-1096 (2005).

99. Barber, D. L. et al. Restoring function in exhausted CD8 T cells during chronic viral infection. Nature 439 682-687 (2006).

This paper documents spectacular mouse observations that show the reversal of T-cel exhaustion in chronic viral infections after the blockade of the PD-1-B7-H1 co-inhibitory pathway. These data support clinical trials in cancer and chronic viral infections with a similar strategy based on mAbs.

100. Nguyen, L. T. et al. Cross-linking the B7 family molecule B7-DC directly activates immune functions of dendritic cells. J. Exp. Med. 196, 1393-1398 (2002).

101. Radhakrishnan, S. et al. Immunotherapeutic potential of B7-DC (PD-L2) cross-linking antibody in conferring antitumor immunity Cancer Res. 64, 4965-4972 (2004)

102. Reis e Sousa, C. Dendritic cells in a mature age. Nature Rev. Immunol. 6, 476-483 (2006).

103. Quezada, S. A., Jarvinen, L. Z., Lind, E. F. \& Noelle, R. J. CD40/CD154 interactions at the interface of tolerance and immunity. Annu. Rev. Immunol. 22, 307-328 (2004)

104. Geldart, T. \& Illidge, T. Anti-CD 40 monoclona antibody. Leuk. Lymphoma. 46, 1105-1113 (2005)

105. Schoenberger, S. P., Toes, R. E., van der Voort, E. I. Offringa, R. \& Melief, C. J. T-cell help for cytotoxic T lymphocytes is mediated by CD40-CD40L interactions. Nature 393, 480-483 (1998)

106. Ridge, J. P., Di Rosa, F. \& Matzinger, P. A conditioned dendritic cell can be a temporal bridge between CD4+ T-helper and a T-killer cell. Nature 393 474-478 (1998)

107. French, R. R., Chan, H. T. Tutt, A L \& Glennie, M. J. CD40 antibody evokes a cytotoxic T-cell response that eradicates lymphoma and bypasses T-cell help. Nature Med. 5, 548-553 (1999).

A ground-breaking paper that used mouse models of lymphoma to show the potential for anti-CD40 mAbs whose mechanism of action depended on the activity of the host immune system. Mechanistic studies showed that treatment with this antibody increased anti-tumour cellular immunity functioning on the cells presenting tumour antigens.

108. Luft, T. et al. IL-1 $\beta$ enhances CD40 ligand-mediated cytokine secretion by human dendritic cells (DC): a mechanism for $\mathrm{T}$ cell-independent $\mathrm{DC}$ activation. J. Immunol. 168, 713-722 (2002).

109. Tutt, A. L. et al. T cell immunity to lymphoma following treatment with anti-CD40 monoclonal antibody. J. Immunol. 168, 2720-2728 (2002)

110. Kikuchi, T., Moore, M. A. \& Crystal, R. G. Dendritic cells modified to express CD40 ligand elicit therapeutic immunity against preexisting murine tumors. Blood 96, 91-99 (2000).

111. Wierda, W. G. et al. CD40-ligand (CD154) gene therapy for chronic lymphocytic leukemia. Blood 96 2917-2924 (2000)

112. Vonderheide, R. H. et al. Phase I study of recombinant human CD40 ligand in cancer patients. J. Clin. Oncol. 19, 3280-3287 (2001)

113. Advani, R. H. et al. Proceedings of the 47th Annual Meeting and Exposition of the American Society Hematology, Atlanta. abst. 1504 (2005)

114. Gladue et al. In vivo efficacy of the CD40 agonist antibody CP-870,893 against a broad range of tumor types: impact of tumor CD40 expression, dendritic cells, and chemotherapy. J. Clin. Oncol. Asco Annual meeting proceedings Vol 24, No $18 \mathrm{~S}$ (June 20 Supplement), 2006: 2514

115. Vonderheide et al. Clinical activity and immune modulation in cancer patients treated with $\mathrm{CP}$ 870,893, a novel CD40 agonist monoclonal antibody. J. Clin. Oncol. 2006 ASCO Annual Meeting Proceedings Vol 24 No. 18S (June 20 Supplement), 2006: 2507.

116. Demaria, S. et al. Immune-mediated inhibition of metastases after treatment with local radiation and CTLA-4 blockade in a mouse model of breast cancer. Clin. Cancer Res. 11, 728-734 (2005)

117. Mokyr, M. B., Kalinichenko, T., Gorelik, L. \& Bluestone, J. A. Realization of the therapeutic potential of CTLA-4 blockade in low-dose chemotherapy-treated tumor-bearing mice. Cancer Res. 58, 5301-5304 (1998)

118. McMillin, D. W. et al. Complete regression of large solid tumors using engineered drug-resistant hematopoietic cells and anti-CD137 immunotherapy. Hum. Gene Ther. 17, 798-806 (2006).

119. Tirapu, I. et al. Improving efficacy of interleukin-12transfected dendritic cells injected into murine colon cancer with anti-CD137 monoclonal antibodies and alloantigens. Int. J. Cancer. 110 51-60 (2004)

120. Uno, T. et al. Eradication of established tumors in mice by a combination antibody-based therapy. Nature Med. 12, 693-698 (2006).

A preclinical study that provides the rationale for strategies that use combinations of immunostimulatory mAbs (anti-4-1BB and antiCD40). In addition, it postulates that further combinations with agents that induce tumour cell death could provide even stronger efficacy, presumably by releasing tumour antigens for cross-presentation by professional APCs.

121. Chen, S. H. et al. Rejection of disseminated metastases of colon carcinoma by synergism of IL-12 gene therapy and 4-1BB costimulation. Mol. Ther. 2, 39-46 (2000). This preclinical study provides impressive data on the combination of IL12- based therapy and an immunostimulatory mAb directed to 4-1 BB. This set of results opens new avenues to increase efficacy by exploiting combined treatments of immunostimulatory mAbs with cytokine-based gene therapy strategies that are already in clinical trials

122. Martinet, O. et al. Immunomodulatory gene therapy with interleukin 12 and 4-1BB ligand: long- term remission of liver metastases in a mouse model. J. Natl Cancer Inst. 92, 931-936 (2000).

123. Blazar, B. R. et al. Ligation of 4-1BB (CDw137) regulates graft-versus-host disease, graft-versusleukemia, and graft rejection in allogeneic bone marrow transplant recipients. J. Immunol. 166 3174-3183 (2001)

124. Kim, J. et al. Stimulation with 4-1BB (CD137) inhibits chronic graft-versus-host disease by inducing activationinduced cell death of donor CD4+ $\mathrm{T}$ cells. Blood 105 2206-2213 (2005)

125. Cuadros, C. et al. Vaccination with dendritic cells pulsed with apoptotic tumors in combination with antiOX40 and anti-4-1BB monoclonal antibodies induces T cell-mediated protective immunity in Her-2/neu transgenic mice. Int. J. Cancer 116, 934-943 (2005).

126. Sheridan, C. TeGenero fiasco prompts regulatory rethink. Nature Biotechnol. 24, 475-476 (2006)

127. Suntharalingam, G. et al. Cytokine storm in a phase trial of the anti-CD28 monoclonal antibody TGN1412. N. Engl. J. Med. 355, 1018-1028(2006). A detailed description of the outcome of the acute systemic inflammation caused by a superagonist anti-CD28 mAb given to six healthy individuals. It contains analytical evidence of the biological effects behind the observed nearly-lethal toxicity. The lessons that it provides are important for the design and implementation of future clinical trials with immunostimulatory mAbs.

128. Marshall, E Clinical research. Lessons from a failed drug trial. Science 313, 901 (2006).

129. Drazen, J. M. et al. Volunteers at risk. Cytokine storm in a phase 1 trial of the anti-CD28 monoclonal antibody TGN1412. N. Engl. J. Med. 355. 1060-1061 (2006)

130. Pardoll, D. \& Allison, J. Cancer immunotherapy: breaking the barriers to harvest the crop. Nature Med. 10, 887-892 (2004).

Acknowledgements

We thank A. Melcher, A. Ribas, J. L. Perez-Gracia, J. GómezNavarro, A Arina, O. Murillo, J. Dubrot and J. Prieto for critical reading and helpful discussion. We acknowledge financial support from Comisión Interministerial de Ciencia y Tecnología (CICYT), Gobierno de Navarra (Departamentos de Salud y Educaciōn) and Redes Temáticas de Investigación Cooperativa FIS, Asociaciōn española contra el cáncer (AECC) and UTE-project-CIMA.

Competing interests statement

The authors declare no competing financial interests.

DATABASES

The following terms in this article are linked online to:

Entrez Gene:

http://www.ncbi.nlm.nih.gov/entrez/query.fcgi?db=gene 4-1BB |B7-DC |B7-H1 |BCL2 |BCL-X | BFL1 CD28 |CD40 CD40L |CD80 |CD86 | CTLA-4 |DR5 | IFN $\gamma \mid$ | IL2 | IL10 |IL12 IL15 | IL23 | FOXP3 | GMCSF | PD-1 | TGF $\alpha$ | VEGF

FURTHER INFORMATION

Clinical trial NCT00309023

http://clinicaltrials.gov/ct/gui/show/NCT00309023

Clinical trial NCT00351325:

http://clinicaltrials.gov/ct/gui/show/NCT00351325 UK Department of Health report on phase I clinical trials: http://www.dh.gov.uk/Consultations/ClosedConsultations/ ClosedConsultationsArticle/fs/en?CONTENT_ ID $=4139038$ \& chk $=\mathrm{Heo5Fe}$

SUPPLEMENTARY INFORMATION

See online article: S1 (box) |S2 (box)

Access to this links box is available online. 